\title{
Epstein-Barr Encoding Region in situ Hybridization
}

National Cancer Institute

\section{Source}

National Cancer Institute. Epstein-Barr Encoding Region in situ Hybridization. NCI

Thesaurus. Code C138177.

Any of various in situ hybridization methods for the detection of latent Epstein-Barr virus (EBV) in tissue sections or other samples. The two small noncoding RNAs, Epstein-Barr encoding region (EBER)-1 and EBER-2, are ubiquitously expressed in all known EBV latency states. 